\title{
Distortional buckling critical sectional dimensions and effective length of cold-formed steel lipped channel members
}

\author{
Guo Yanli ${ }^{1,2}$, Hu Pengwen ${ }^{1 *}$, Li Xiao ${ }^{1}$, Yao Xingyou ${ }^{1,2}, X$ Bin $^{1,2}$ \\ ${ }^{1}$ School of Civil and Architectural Engineering, Nanchang Institute of Technology, Nanchang, 330099, China; \\ ${ }^{2}$ Jiangxi Province Key Laboratory of Hydraulic \& Civil Engineering Infrastructure Security, Nanchang, 330099, China;
}

\begin{abstract}
Based on the comparison on buckling stability coefficient between local and distortional buckling, the critical cross-sectional dimensions without considering the distortional buckling for cold-formed steel lipped channel members are put forward. Furthermore, the critical effective length of nonoccurrence of distortional buckling is presented. The research results show that the calculation of distortional bucking strength of cold-formed steel lipped channel members can be avoided by controlling the reasonable cross-sectional dimensions or the effective length.
\end{abstract}

\section{Introduction}

Cold-formed lipped channel sections have been widely used in light gauge steel construction. These channel members may buckle in one and several modes including local buckling, distortional buckling, and overall buckling based on different boundary conditions, sections, and the effective length. Local buckling involves distortion of the cross section with only rotation occurring at interior fold lines of the section. Distortional buckling involves distortion of the cross section with rotation and translation occurring at interior fold lines. Overall buckling excludes distortion of the cross section, however, translation and rotation of the entire cross section occur. Meanwhile, the local buckling mode occurs with repeated waves at a short length, while overall buckling occurs in one half-wave over the length of the member. Distortional buckling occurs at a wavelength intermediate to the two other modes. Cold-formed steel members must carefully consider the role of cross-section instability in their design.

North American specification for the design of cold-formed steel structural members (AISI-S100 2010) [1] and Australian/New Zealand standard cold-formed steel structures (AS/NZS4006 2005) [2] both apply an effective width method for determining the design strength of channel members. The effective width method introduced by von Karman et al. in 1932[3] and modified by Winter [4]. The two key shortcomings identified were lack of a consistent treatment for the interaction of elements in local buckling, and inadequate provisions to handle distortional buckling. Chinese code Technical code of cold-formed thin-walled steel structures(GB50018-2002)[11] also use the effective width method to calculate the strength of these cold-formed lipped channel sections, in which the interaction of elements in local buckling are considered and the distortional buckling is handled via a lower reduced plate buckling coefficient and experimental results indicated that this simplified method does not always provide consistent predictions. Meanwhile, Chinese researchers [5-10] provided some design methods for distortional buckling including the calculations of the distortional buckling stress and stability coefficient, but these design methods are more complex for designers.

So it is necessary to study on the critical condition of occurrence of distortional buckling in order to avoid the complicated calculate about distortional buckling of cold-formed steel channel members. This paper presents the critical conditions and corresponding design rules of occurrence of distortional buckling based on the distortional-buckling stability coefficient provided in reference [5].

\section{Critical Dimension Without Regard To Distortional Buckling}

Because the calculation of the distortional buckling is complex, the critical condition that the distortional buckling strength can't be considered need be studied. There are two cases for the critical condition of occurrence of distortional buckling. One is that the distortional buckling occurs after the local buckling, and the other is that the distortional buckling does not occur. For the former, the distortional buckling stress is greater than the local buckling stress which means that the distortional buckling stability coefficient is bigger than the local-buckling stability coefficient and the stability coefficient of the partially stiffener element can use the local-buckling stability coefficient, and for the latter, the distortional buckling should not consider because the distortional buckling doesn't occur. 


\subsection{Distortional buckling and local buckling coefficient of plate}

The Eq. (3) is the distortional buckling stability coefficient of the partially stiffened element, which can be found in reference [11].

If the maximum stress acts at the stiffened edge:

$$
k=\frac{b\left[(b / \lambda)^{2} / 3+0.142\right]+10.92 I(b / \lambda)^{2} / t^{3}}{b(1 / 12+\psi / 4)+a \psi}
$$

If the maximum stress acts at the partially stiffened edge:

$$
k=\frac{b\left[(b / \lambda)^{2} / 3+0.142\right]+10.92 I(b / \lambda)^{2} / t^{3}}{b(1 / 4+\psi / 12)+a}
$$

(1b)

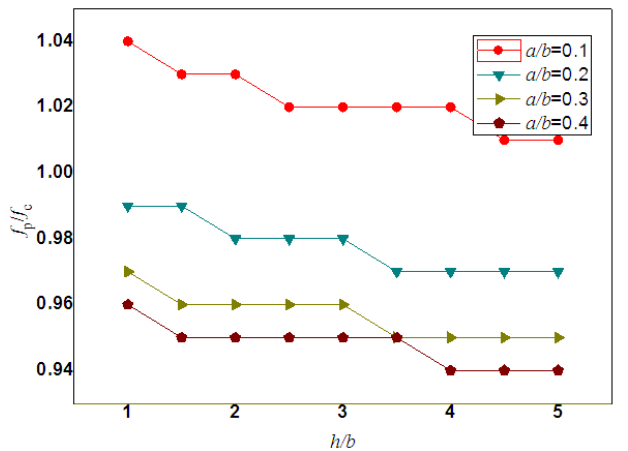

Fig.1 Comparison on distortional buckling stress between the proposed method and the Finite Strip Method

\subsection{Occurrence of distortional buckling being after local buckling}

The occurrence of distortional buckling is after local buckling if the distortional buckling stability coefficient is greater than the local buckling stability coefficient.

If the maximum stress acts at the stiffened edge, the critical condition for the distortional buckling coefficient being greater than local buckling coefficient can be obtained by the Eq. (3).
Where $\lambda$ is the minimum value of the half-wave length of distortional buckling and the effective length of members, $a, b, t, I, \psi$ are the width of the lip, the width of the partially stiffened element, the thickness of the section, moment of inertia of the lip about the centroid axis of the lip and the partially stiffened element, and the factor of non-uniform stress distribution for the partially stiffened element, respectively. As the shown in Fig.1, the distortional buckling stress predicted using equation (1) and finite strip method CUFSM is very close which means than the expression (1) can be used to calculate the distortional buckling coefficient reasonably.

The elastic critical local buckling coefficient of plate can be determined by Eq. (2), which gives

$$
k=2(1-\psi)^{3}+2(1-\psi)+4
$$

$$
2(1-\psi)^{3}+2(1-\psi)+4 \leq \frac{b\left[(b / \lambda)^{2} / 3+0.142\right]+10.92 I(b / \lambda)^{2} / t^{3}}{b(1 / 12+\psi / 4)+a \psi}
$$

The limit value of the lip can be gotten as shown in Table1(a) using the Eq. (3) if the left part of Eq. (3) is assigned to equal the right part of Eq. (3). The geometric

\begin{tabular}{|c|c|c|c|c|c|c|c|c|c|c|c|}
\hline \multirow[b]{2}{*}{$\psi$} & \multirow[b]{2}{*}{$h / b$} & \multicolumn{10}{|c|}{$a / t$} \\
\hline & & $\begin{array}{c}b / t \\
=15\end{array}$ & $\begin{array}{c}b / t \\
=20\end{array}$ & $\begin{array}{c}b / t \\
=25\end{array}$ & $\begin{array}{c}b / t \\
=30\end{array}$ & $\begin{array}{c}b / t \\
=35\end{array}$ & $\begin{array}{c}b / t \\
=40\end{array}$ & $\begin{array}{c}b / t \\
=45\end{array}$ & $\begin{array}{c}b / t \\
=50\end{array}$ & $\begin{array}{c}b / t \\
=55\end{array}$ & $b / t=60$ \\
\hline \multirow{3}{*}{1} & 1 & & & & & & 16.8 & 16.5 & 16.3 & 16.2 & 16.0 \\
\hline & 2 & & & & & & & 23.1 & 23.0 & 22.9 & 22.7 \\
\hline & 3 & & & & & & & & & & 28.4 \\
\hline \multirow{4}{*}{0.8} & 1 & & & & & 15.5 & 15.3 & 15.2 & 14.9 & 14.8 & 14.6 \\
\hline & 2 & & & & & & & 21.3 & 21.0 & 20.8 & 20.5 \\
\hline & 3 & & & & & & & & & 25.7 & 25.4 \\
\hline & 4 & & & & & & & & & & 29.7 \\
\hline \multirow{5}{*}{0.6} & 1 & & & & 13.5 & 13.2 & 13.1 & 13.0 & 13.0 & 12.9 & 12.9 \\
\hline & 2 & & & & & 18.3 & 18.0 & 17.9 & 17.9 & 17.9 & 17.9 \\
\hline & 3 & & & & & & 22.6 & 22.2 & 22.0 & 21,9 & 21.9 \\
\hline & 4 & & & & & & & 25.8 & 25.8 & 25.6 & 25.4 \\
\hline & 5 & & & & & & & & & 28.9 & 28.6 \\
\hline \multirow{2}{*}{0.4} & 1 & 10.8 & 10.6 & 10.4 & 10.4 & 10.5 & 10.6 & 10.7 & 10.9 & 11.0 & 11.1 \\
\hline & 2 & & & & 14.7 & 14.7 & 14.7 & 14.7 & 14.8 & 14.9 & 15.0 \\
\hline
\end{tabular}
limitations of sections are $1 \leq h / b \leq 5 \quad, 15 \leq b / t \leq 60$, $-0.2 \leq \psi \leq 1$.

Table 1(a) Limit value of the lip when maximum stress acts at the stiffened edge 


\begin{tabular}{|c|c|c|c|c|c|c|c|c|c|c|c|}
\hline & 3 & & & & & \multirow[t]{3}{*}{17.8} & \multirow{3}{*}{$\begin{array}{l}17.9 \\
20.5\end{array}$} & 17.9 & \multirow{3}{*}{$\begin{array}{l}18.0 \\
20.6\end{array}$} & \multirow{2}{*}{$\begin{array}{l}18.0 \\
20.7\end{array}$} & \multirow{2}{*}{$\begin{array}{l}18.1 \\
20.8\end{array}$} \\
\hline & 4 & & & & & & & 20.5 & & & \\
\hline & 5 & & & & & & & 23.1 & & 23.2 & 23.2 \\
\hline \multirow{5}{*}{0.2} & 1 & 7.2 & 7.4 & 7.6 & 7.8 & 8.0 & 8.2 & 8.3 & 8.5 & 8.7 & 8.9 \\
\hline & 2 & & 10.3 & 10.4 & 10.5 & 10.7 & 10.9 & 11.1 & 11.3 & 11.5 & 11.7 \\
\hline & 3 & & & 12.7 & 12.7 & 12.9 & 13.0 & 13.2 & 13.4 & 13.6 & 13.8 \\
\hline & 4 & & & & 14.5 & 14.6 & 14.8 & 15.0 & 15.2 & 15.4 & 15.6 \\
\hline & 5 & & & & & 16.3 & 16.4 & 16.6 & 16.7 & 16.9 & 17.1 \\
\hline \multirow{5}{*}{0} & 1 & 3.8 & 4.2 & 4.5 & 4.8 & 5.0 & 5.2 & 5.4 & 5.6 & 5.8 & 6.0 \\
\hline & 2 & 4.8 & 5.3 & 5.7 & 6.0 & 6.4 & 6.6 & 6.9 & 7.1 & 7.4 & 7.6 \\
\hline & 3 & 5.5 & 6.0 & 6.5 & 6.9 & 7.3 & 7.6 & 7.9 & 8.2 & 8.5 & 8.7 \\
\hline & 4 & 6.0 & 6.6 & 7.2 & 7.6 & 8.0 & 8.4 & 8.7 & 9.0 & 9.3 & 9.6 \\
\hline & 5 & 6.5 & 7.2 & 7.7 & 8.2 & 8.6 & 9.0 & 9.4 & 9.7 & 10.0 & 10.3 \\
\hline \multirow{5}{*}{-0.2} & 1 & 0.7 & 0.9 & 1.1 & 1.2 & 1.4 & 1.5 & 1.6 & 1.7 & 1.8 & 1.9 \\
\hline & 2 & 0.9 & 1.1 & 1.3 & 1.5 & 1.7 & 1.8 & 2.0 & 2.1 & 2.3 & 2.4 \\
\hline & 3 & 1.0 & 1.2 & 1.4 & 1.7 & 1.8 & 2.0 & 2.2 & 2.3 & 2.5 & 2.6 \\
\hline & 4 & 1.0 & 1.3 & 1.5 & 1.8 & 2.0 & 2.2 & 2.3 & 2.5 & 2.7 & 2.8 \\
\hline & 5 & 1.0 & 1.3 & 1.6 & 1.8 & 2.1 & 2.3 & 2.5 & 2.6 & 2.8 & 3.0 \\
\hline
\end{tabular}

It can be found from Table 1(a) that the limit value of the lip can approximately use the limit value the width-to-thickness ratio of the lip has only small changes with the change of the width-to-thickness ratio of the partially stiffened element. So the limit value of corresponding to that of that width-to-thickness ratio of the partially stiffened element equal 60 as shown in Table 1(b) and Fig.2.

Table 1(b) Limit value approximately of the lip when maximum stress acts at the stiffened edge

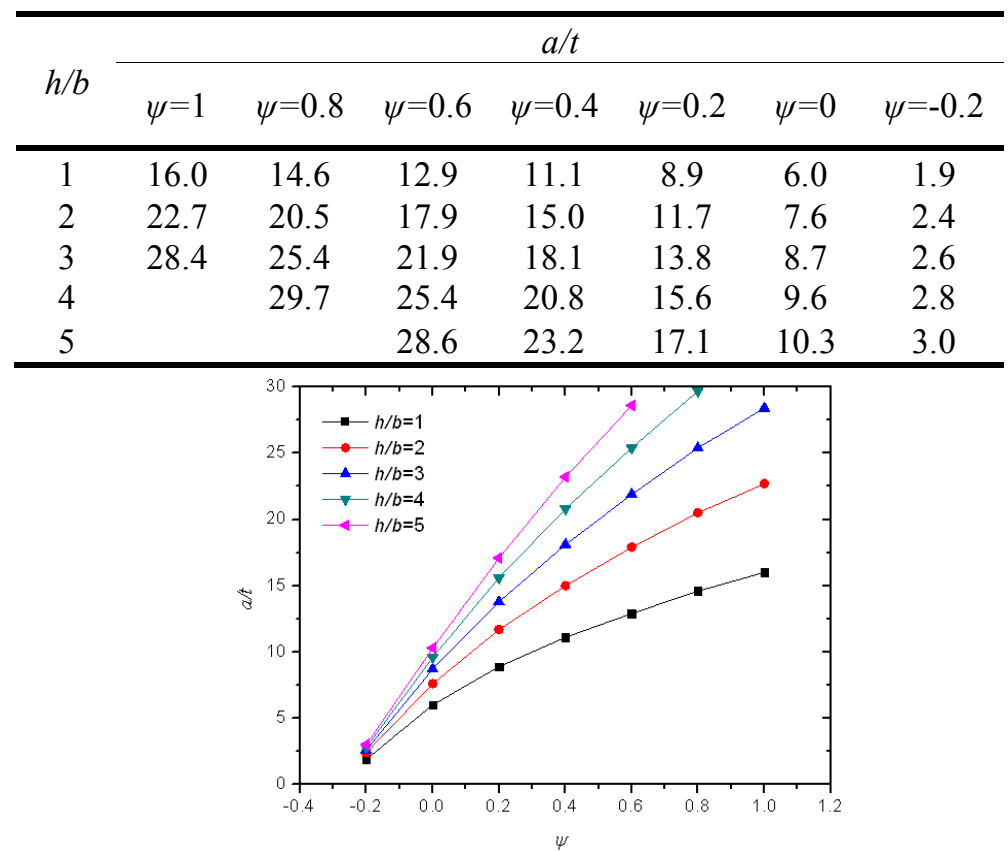

Fig.2 Limit value approximately of the lip when maximum stress acts at the stiffened edge

As shown in Fig. 2, the relationship between Limit value approximately of the lip $a / t$ and $\psi$ can be expressed with binomial curve for the different value of $h / b$. So the limit value of width-to-thickness ratio of the lip can be given as Eq. (4) when the maximum stress acts at the stiffener edge according to regression analysis. The geometric and stress limitations of sections are- $1 /(3+12 a / b)<\psi \leq 1, a / b \leq 0.5,1 \leq h / b \leq 5$.

$a / t \geq\left(0.017\left(\frac{h}{b}\right)^{2}-0.092 \frac{h}{b}-0.164\right) \psi^{2}-\left(0.902 \frac{h}{b}-0.653\right) \psi+6.896 \frac{h}{b}+9.74$
If the maximum stress acts at the partially stiffened edge, the critical condition for the distortional buckling coefficient being greater than local buckling coefficient can be obtained by the Eq. (5).

$2(1-\psi)^{3}+2(1-\psi)+4 \leq \frac{b\left[(b / \lambda)^{2} / 3+0.142\right]+10.92 I(b / \lambda)^{2} / t^{3}}{b(1 / 4+\psi / 12)+a}$

The limit value of the lip can be gotten as shown in Table2 using the Eq. (5) if the left part of Eq. (5) is assigned to equal the right part of Eq. (5). The geometric limitations of sections are $1 \leq h / b \leq 5,15 \leq b / t \leq 60,-0.2 \leq \psi \leq 1$. 
The limit value that is not given in Table 2 is that limit value is greater than the half of the width of the web.

Table 2 Limit value of the lip when maximum stress acts at the partially stiffened edge

\begin{tabular}{|c|c|c|c|c|c|c|}
\hline \multirow{2}{*}{$\psi$} & \multirow{2}{*}{$h / b$} & \multicolumn{5}{|c|}{$a / t$} \\
\hline & & $b / t=40$ & $b / t=45$ & $b / t=50$ & $b / t=55$ & $b / t=60$ \\
\hline \multirow{6}{*}{1} & 1 & 16.8 & 16.5 & 16.3 & 16.2 & 16.0 \\
\hline & 1.2 & 18.2 & 18.1 & 17.9 & 17.5 & 17.2 \\
\hline & 1.5 & 19.3 & 19.0 & 19.0 & 18.8 & 18.7 \\
\hline & 1.8 & & 20.7 & 20.5 & 20.5 & 20.3 \\
\hline & 2.0 & & & 23.2 & 22.9 & 22.7 \\
\hline & 2.2 & & & & & 25.9 \\
\hline \multirow{4}{*}{0.9} & 1 & & 22.5 & 21.5 & 20.8 & 20.3 \\
\hline & 1.2 & & & 24.5 & 23.5 & 22.9 \\
\hline & 1.5 & & & & 27.6 & 26.6 \\
\hline & 1.8 & & & & & 30.3 \\
\hline \multirow{4}{*}{0.8} & 1 & & & 22.7 & 21.9 & 21.37 \\
\hline & 1.2 & & & & 24.9 & 24.1 \\
\hline & 1.5 & & & & 29.3 & 28.2 \\
\hline & 1.8 & & & & & 32.3 \\
\hline \multirow{3}{*}{0.6} & 1 & & & & 24.9 & 24.1 \\
\hline & 1.2 & & & & 28.5 & 27.4 \\
\hline & 1.5 & & & & & 32.4 \\
\hline \multirow{3}{*}{0.4} & 1 & & & & 29.7 & 28.4 \\
\hline & 1.2 & & & & & 32.7 \\
\hline & 1.5 & & & & & 39.4 \\
\hline
\end{tabular}

It also can be found from Table 2 that the limit value of the width-to-thickness ratio of the lip has only small changes with the change of the width-to-thickness ratio of the partially stiffened element. So the limit value of the lip can approximately use the limit value corresponding to that of that width-to-thickness ratio of the partially stiffened element equal 60 . But the section that the stability coefficient of distortional buckling is less than that of local buckling is very few. So the effect of distortional buckling on overall buckling strength should be considered for all members which the maximum stress acts at the partially stiffener edge.

If the member bends about strong axial the critical condition for the distortional buckling coefficient being greater than local buckling coefficient can be obtained by the Eq. (6).

$$
4 \leq \frac{b\left[(b / \lambda)^{2} / 3+0.142\right]+10.92 I(b / \lambda)^{2} / t^{3}}{b / 3+a}
$$

The limit value of the lip can be gotten as shown in Table3 using the Eq. (6) if the left part of Eq. (6) is assigned to equal the right part of Eq. (6). The geometric limitations of sections are $1 \leq h / b \leq 5,15 \leq b / t \leq 60,-0.2 \leq \psi \leq 1$. The limit value that is not given in Table 2 is that limit value is greater than the half of the width of the web.

Table 3(a) Critical dimension of lips for bending members about strong axis

\begin{tabular}{|c|c|c|c|c|c|c|c|c|c|c|}
\hline \multirow{2}{*}{$h / b$} & \multicolumn{10}{|c|}{$b / t$} \\
\hline & 15 & 20 & 25 & 30 & 35 & 40 & 45 & 50 & 55 & 60 \\
\hline 1 & & & & 15.4 & 14.4 & 13.8 & 13.5 & 13.3 & 13.2 & 13.1 \\
\hline 2 & & & & & & & 21.2 & 20.4 & 19.8 & 19.4 \\
\hline 3 & & & & & & & & 27.2 & 26.0 & 25.1 \\
\hline 4 & & & & & & & & & & 30.8 \\
\hline 5 & & & & & & & & & & 36.6 \\
\hline
\end{tabular}

It also can be found from Table 3(a) that the limit value of the width-to-thickness ratio of the lip has only small changes with the change of the width-to-thickness ratio of the partially stiffened element. So the limit value of the lip can approximately use the limit value corresponding to that of that width-to-thickness ratio of the partially stiffened element equal 60 as shown in Table 3(b) .
Table 3(b) Critical dimension of lips for bending members about strong axis

\begin{tabular}{cccccc}
\hline$h / b$ & 1 & 2 & 3 & 4 & 5 \\
\hline$a / t$ & 13.1 & 19.4 & 25.1 & 30.8 & 36.6 \\
\hline
\end{tabular}

As shown in Table 3, the relationship between Limit value approximately of the lip $a / t$ and $\psi$ can be expressed with linear curve for the different value of $h / b$. So the 
limit value of width-to-thickness ratio of the lip can be given as Eq. (7) when the member bends about strong axis according to regression analysis.

$$
a / t \geq 5.84(h / b)+7.48
$$

\subsection{Critical condition for nonoccurrence of distortional buckling}

It is no necessary to consider the decrease affect of distortional buckling on load-carrying capacities of members when distortional buckling does not occur. Then the critical condition is that the distortional buckling strength is maximum than overall buckling strength.

1)Axially-compressed members

The distortional buckling strength and the overall buckling strength of axially-compressed members can be predicted as follows:

$$
\begin{gathered}
P_{c d}=\left[\left(0.6 f_{c d} / f_{y}\right)^{1 / 4}-0.1\right] A_{e} f_{y} \\
P_{e}=\varphi f_{y} A_{e}
\end{gathered}
$$

Where $A_{\mathrm{e}}, f_{\mathrm{y}}, \varphi, f_{\text {cd }}$ are the effective area, the yield stress, overall buckling stability factor of member, and distortional buckling stress of member, respectively.

So the critical condition without occurrence of distortional buckling for axially-compressive members can be obtained as Eq. (10a), which can be simplified as Eq. (10b).

$$
\begin{gathered}
P_{c d}=\left[\left(0.6 f_{c d} / f_{y}\right)^{1 / 4}-0.1\right] A f_{y} \geq P_{e}=\varphi f_{y} A \\
{\left[\left(0.6 f_{c d} / f_{y}\right)^{1 / 4}-0.1\right] \geq \varphi}
\end{gathered}
$$

The Eq.(10b) can be rewritten as follows:

$$
\lambda=\sqrt{f_{y} / f_{c d}} \leq 0.774 /(\varphi+0.1)^{2}
$$

2) Eccentrically-compressed members and bending members instability about strong axis

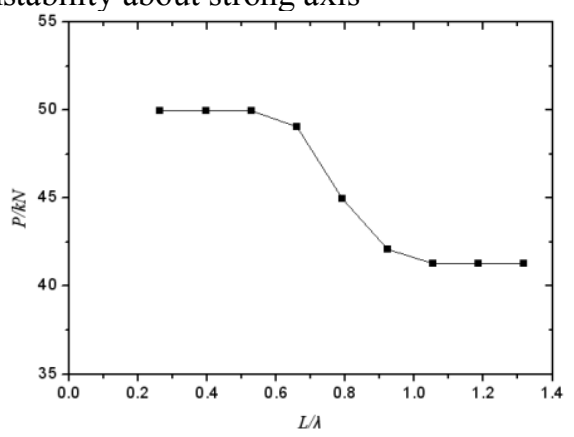

(a) Distortional buckling strength vs. nominal effective length of members
If distortional buckling doesn't occur for the eccentrically-compressed members and bending members the partially stiffened element must be full effective. Then the calculated formula can be attained as Eq. (12) referring to Eq. (11) for axially-compressed members and assigning that the overall buckling stability factor of member equals 1 .

$$
\lambda=\sqrt{f_{y} / f_{c d}} \leq 0.64
$$

\section{Critical Length Without Regard To Distortional Buckling}

The nominal effective length should be used to calculate the elastic distortional buckling stress in equations (2) and (3) when the nominal effective length is less than the distortional buckling wave length. The distortional buckling strength can increase with the increase of the elastic distortional buckling stress because of the decrease of the nominal effective length. So the relationship of the distortional buckling strength and nominal effective length of members should be considered.

The axially loaded lipped channel members with that the width of the web, the width of the partially stiffened plate, the width of the lip, the thickness of members, and the yield strength are $210 \mathrm{~mm}, 60 \mathrm{~mm}, 15 \mathrm{~mm}, 1 \mathrm{~mm}$, and $345 \mathrm{MPa}$ are selected to design. The distortional buckling wave length of this member under axial load and bending load are 758.47 and $637.80 \mathrm{~mm}$, respectively. The nominal effective length of members are from 200 to $1000 \mathrm{~mm}$.The Fig. 3(a) shows the relationship between the distortional buckling strength and the nominal effective length of axially loaded members. The comparison on distortional buckling strength between that predicted using Chinese code and equation (3) and that calculated using Chinese code in which the buckling coefficient of the partially stiffened element equal 4 is shown in Fig.3(b).

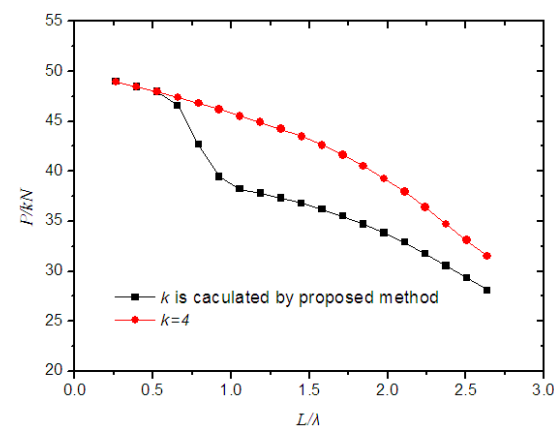

(b)Comparison on distortional buckling strength between proposed equation (3) and the partially stiffened element as stiffened element

Fig.3 Distortional buckling strength vs. nominal effective length of distortional buckling of axially-compressed members

As shown in Fig. 3(a), the distortional buckling strength and the buckling coefficient of the partially stiffened element of the lipped channel member under axially compression have no change when the nominal effective length of member is greater than the distortional buckling wave length or less than the half of the distortional buckling wave length. The distortional buckling strength has a rapid change when the nominal effective length is between half and one distortional buckling wave length which shows that the nominal 
effective length has a great affect on distortional buckling strength.As shown in Fig.3(b), the load-carrying capacities of members is equal to that calculated using Chinese code and assigning the buckling coefficient of the partially stiffened element as 4 when the nominal effective length of member is less than the half of the distortional buckling wave length buckling, which means that distortional buckling doesn't occur. The load-carrying capacities of members predicted using Chinese code and equation (3) and calculated using Chinese code in which the buckling coefficient of the partially stiffened element equal 4 have large different when the the nominal effective length of member is between half and one distortional buckling wave length.

The comparison on distortional buckling strength for

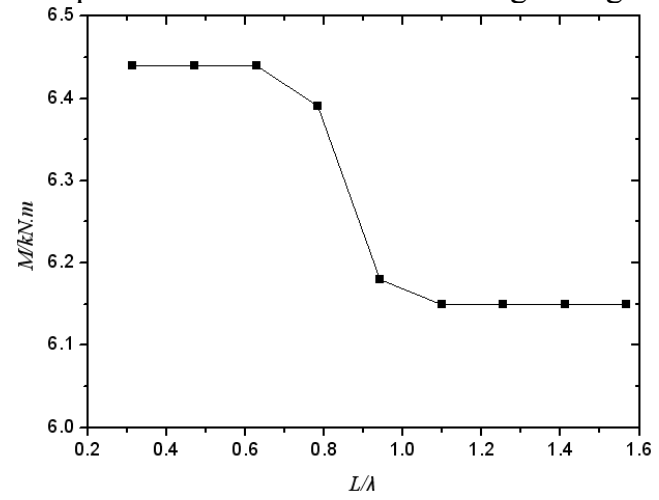

Fig.4 Distortional buckling strength vs. nominal effective length of distortional buckling of bending members

\section{Conclusion}

1) By comparing the stability coefficients of local and distortional buckling, the critical condition of distortional buckling of the lipped channel section member after local buckling is obtained, that is, the critical dimensions of the buckling, and then the stability coefficients of some stiffened plates during the calculation of bearing capacity can be obtained at the time of local buckling, which greatly simplifies the bearing capacity analysis.

2) By comparing the distortional buckling load with the overall stable bearing capacity, the critical condition that the distortional buckling of the axial compression member, the bending member and the bending member of the coil-side lipped channel section does not occur is obtained, and the influence of distortional buckling can be ignored in the calculation of bearing capacity.

3) The analysis shows that when the calculated length of distortional buckling is less than half of the half wavelength of distortional buckling, the influence of distortional buckling is not considered.

\section{Acknowlegements}

The author gratefully acknowledgements the financial support provided by Department of Education Science and Technology Projects of Jiangxi Province in China (No: GJJ180932, GJJ170983), National Natural Science Foundation Projects of China (No:51868049), Natural Science Foundation Projects of Jiangxi Province in bending members and eccentrically-compressed members between that predicted using Chinese code and equation (3) and that calculated using Chinese code in which the partially stiffened element is as a stiffened element are shown in Fig.4 and Fig.5, respectively. The eccentric distance of eccentrically-compressed members equal 0.3 multiplying the width of the partially stiffened element. The compared results for bending members and eccentrically-compressed members as shown Fig.4 and Fig.5 all have the same law as that of the axially-compressed members. So the critical length without regard to distortional buckling is that the nominal effective length of the lipped channel member is less than the half of the distortional buckling wave length.

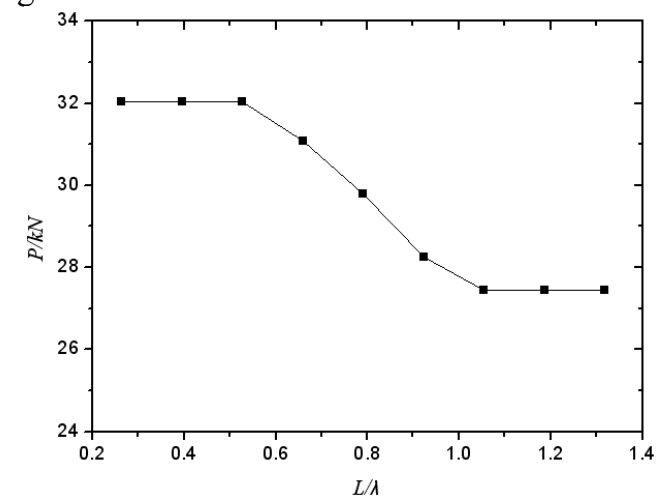

Fig.5 Distortional buckling strength vs. nominal effective length of distortional buckling of eccentrically-compressed members

China (No:20181BAB206040), and Academic and Technical Leaders in Major Subject Areas projects of Jiangxi Province in China(No: 20172BCB22022).

\section{Reference}

1. AISI-S100-2007. North American cold-formed steel specification.

2. AS/NZS4600:2005. Australian/New Zealand standard cold-formed steel structures.

3. Von Karman T. Sechler EE. Donnel LH. The strength of thin plates in compression. Transactions, ASME 1932;54 APM 5405

4. Winter G. Strength of thin steel compression flanges. Transactions of ASCE, Paper No.2305, 112,1 .

5. Yao,X.Y. (2012) Distortional buckling behavior and design method of cold-formed thin-walled steel members with opening section. Shanghai: Tongji University, 129-200(in Chinese)

6. Yao,J. (2008) Distortional buckling loads of cold-formed lipped channels. Engineering Mechanics, 25(12):30-34. (in Chinese)

7. Zhen, J. C., Yao,J. (2008) Reinforcing and finite element analysis on distortional buckling of cold-formed channel beams. Low temperature architecture technology, 124(5):32-52. (in Chinese)

8. Chen, S.F. (2002) Local interactive bucking and distortional buckling of lipped channels. Journal of 
Building Structures, 23(1):27-32. (in Chinese)

9. Li,Y.Q., Wang, S.K., Shen, Z.Y., et al.(2016) Experimental study and load-carrying capacity analysis of high-strength cold-formed thin-walled steel lipped channel columns under axial compression. Journal of Building Structures, 31(11):17-25. (in Chinese)

10. Li,Y. Q.,Li,X., Shen, Z.Y., et al.(2016) Experimental study and load-carrying capacity analysis of eccentrically-compressed high-strength cold-formed thin-walled steel lipped channel columns. Journal of Building Structures, 31(11):26-35. (in Chinese)

11. GB50018-2002.Technical code of cold-formed thin-wall steel structures. (in Chinese) 